\title{
Association between Metabolic Syndrome and Urolithiasis- Descriptive Study
}

\author{
Philipraj SJ ${ }^{1 *}$, Purwar R ${ }^{1}$, Balabhaskar Reddy ${ }^{1}$ and Vishnuvardhan ${ }^{2}$ \\ ${ }^{1}$ Department of Urology, Sri Balaji Vidyapeeth University, India \\ ${ }^{2}$ Department of Statistics, Pondicherry University, India
}

*Corresponding author: Philipraj SJ, Department of Urology, Mahatma Gandhi

\section{Research Article}

Volume 3 Issue 4

Received Date: September 24, 2018

Published Date: October 10, 2018

Medical College and Research Institute- Sri Balaji Vidyapeeth University, India, Email: josephphilipraj@gmail.com

\section{Abstract}

The prevalence of kidney stones has been on the rise over the last 2 decades worldwide. Many studies have indicated a possible association between metabolic syndrome and kidney stone disease. Several hypotheses have been proposed to explain the pathophysiology of urolithiasis resulting from metabolic syndrome, amongst which are the insulin resistance and Randall's plaque hypothesis. Newer terminologies like Metabesity and Diabesity have been mentioned in recent literature. Many studies have found factors contributing to urolithiasis in patients suffering from metabolic syndrome, out of which obesity, overweight, and sedentary lifestyles have been identified as major etiological factors. This study is done to assess the association of urolithiasis and metabolic syndrome.

Keywords: Metabolic Syndrome; Urolithiasis; Metabesity; Diabesity

Abbreviations: WHO: World Health Organization; BPH: Benign Prostatic Hyperplasia; VLDL: Very-LowDensity Lipoproteins; HDL-C: High-Density Lipoprotein Cholesterol; EGIR: European Group for the Study of Insulin Resistance; NCEP-ATP-3: National Cholesterol Education Program Adult Treatment Panel- III; IDF: International Diabetes Foundation; AHA: American Heart Association; NHLBI: National Heart, Lung, and Blood Institute; BMI: Body Mass Index; WC: Waist Circumference; SHT: Systemic Hypertension; TG: Triglycerides; HDL: High Density Lipoprotein; DM: Diabetes Mellitus.

\section{Introduction}

Urolithiasis is one of the most common disorders of the urinary tract. A large number of people are suffering from urolithiasis all over the globe [1]. It is most common between third to sixth decades of life. Men are more commonly affected than women [2]. In India, $12 \%$ of the population is expected to have urinary stones [3]. Recurrent stone formation is a common problem with all types of stones and therefore preventive measures are an important part of the care of patients with urolithiasis. Etiopathogenesis of stones is multifactorial. Recent studies have suggested that obesity is a significant contributing factor to urolithiasis. World Health Organization (WHO) estimation is that 1.7 billion people are overweight and obese worldwide [4]. An increased incidence of urolithiasis of greater than $75 \%$ is seen in overweight and obese patients compared to their normal counterparts [5].

Metabolic syndrome is a worrying entity which is not only prevalent in the developed countries but also in 
developing countries like India. Its correlation with the cardiovascular diseases has been well established [6]. However, some studies $[7,8]$ have indicated a significant correlation between metabolic syndrome and urolithiasis. As urolithiasis, metabolic syndrome or Syndrome $\mathrm{X}$ is also multifactorial. Several epidemiological studies [9-11] have focused on the search for a pathophysiological relationship between the different components of this syndrome (obesity, hypertension, diabetes, dyslipidaemia) and urological problems. Most established aspects of the metabolic syndrome are linked to benign prostatic hyperplasia (BPH) and prostate cancer. Fasting plasma insulin, in particular, has been linked to BPH and incident, aggressive and lethal prostate cancer [12-15]. The metabolic syndrome has also been shown to be associated with non-prostatic urological conditions such as male hypogonadism, nephrolithiasis, overactive bladder and erectile dysfunction, although data on these conditions are still sparse and not definite.

Reaven coined the term 'syndrome $\mathrm{X}$ ' for this conglomeration of various metabolic abnormalities $[16,17]$, including glucose intolerance, hypertension, increased very-low-density lipoproteins (VLDL), triglycerides, and decreased high-density lipoprotein cholesterol (HDL-C), with insulin resistance being the basic underlying pathophysiologic problem. Over the last two decades, various organizations like World Health Organization (WHO 1998), European Group for the Study of Insulin Resistance (EGIR) (1999), National Cholesterol Education Program Adult Treatment Panel- III (NCEPATP-3) (2001), International Diabetes Foundation (IDF) (2005) and American Heart Association /National Heart, Lung, and Blood Institute (AHA/NHLBI) (2005) have proposed different definitions, using varying terminologies for metabolic syndrome [18-22].

New addition to the glossary of terms is the concept of diabesity. Diabesity is a combination of diabetes and obesity. Recently, Dr. Alexander Fleming who is an endocrinologist added a different dimension to the definition of metabolic syndrome by introducing the concept of metabesity (2013). According to Dr. Fleming, metabesity describes all relevant conditions (diabetes mellitus, obesity, metabolic syndrome, cardiovascular disease, dyslipidaemia $\geq$, cancer promoting factors and accelerated aging) which impose a serious burden on healthcare, and economic state [23].

\section{American Heart Association}

Metabolic syndrome occurs when a person has three or more of the following measurements: a. Abdominal obesity (Waist circumference $>40$ inches in men, and $>35$ inches in women).

b. Triglyceride level of $\geq 150$ milligrams per $\mathrm{dl}$ of blood.

c. HDL cholesterol of less than $<40 \mathrm{mg} / \mathrm{dL}$ in men or $<50$ $\mathrm{mg} / \mathrm{dL}$ in women.

d. Systolic blood pressure (top number) of $\geq 130 \mathrm{~mm} \mathrm{Hg}$, or diastolic blood pressure (bottom number) of $\geq 85$ $\mathrm{mm} \mathrm{Hg}$.

e. Fasting glucose of $\geq 100 \mathrm{mg} / \mathrm{dl}$.

Objectives: This is a prospective descriptive study. The objectives of this study are to:

a. analyse the correlation between various components of metabolic syndrome and urolithiasis

b. analyse relation between certain lifestyle factors like smoking, alcoholism and urolithiasis

\section{Patients and Methods}

All patients who attended the urology OPD in MGMCRI, Pondicherry between Jan 2017 and July 2018 were enrolled in this study. The diagnosis of metabolic syndrome was based on AHA criteria. Blood pressure was measured with mercury sphygmomanometer. Subjects whose reading was higher than $130 \mathrm{mmHg}$ (systolic) or $85 \mathrm{mmHg}$ (diastolic) (average of 3 values at $1 \mathrm{~min}$ interval) and those who reported to be under antihypertensive drugs were considered hypertensive. Participants whose fasting glucose was equal to or above $100 \mathrm{mg} / \mathrm{dl}$ and those who reported oral use of hypoglycaemic agents and/or insulin were considered diabetic. Body weight was measured by electronic weighing machine. The body mass index (BMI) was calculated as the ratio of weight (in kilograms) and squared height $-\mathrm{BMI}=$ Weight $(\mathrm{kg}) /$ Height $(\mathrm{m})^{2}$ (Table 1$)$.

\begin{tabular}{|c|c|}
\hline Under 18.5 & Underweight \\
\hline $18.5-24.9$ & Healthy weight range \\
\hline $25.0-29.9$ & Overweight \\
\hline $30.0-34.9$ & Obesity I \\
\hline $35.0-39.9$ & Obesity II \\
\hline 40.0 (and above) & Obesity III \\
\hline
\end{tabular}

Table 1: Showing Overweight \& Obesity.

Waist circumference was assessed on three occasions using an inextensible tape-measure, at the midpoint of the distance between the iliac crest and the last costal margin, with the patient upright and at expiration. Biochemical serum parameters were obtained after $8 \mathrm{~h}$ of fasting. Standard serum parameters included glucose, total cholesterol, Low-density lipoprotein-cholesterol, HDL-C, triglycerides. 


\section{Statistical Analysis}

The study is about observing the association between various parameters of metabolic syndrome and Urolithiasis. The parameters related to metabolic syndrome are Waist Circumference (WC), Systemic Hypertension (SHT), Triglycerides (TG), High density Lipoprotein (HDL), Body Mass Index (BMI) and Diabetes mellitus (DM). All these were coded as nominal variables. Association was observed using statistical test -ChiSquare test and all the results were compared at 0.05 level. Multiple Bar diagrams are depicted to show the distribution of cases with respect to categories of metabolic syndrome and Urolithiasis. The entire analysis is carried out using IBM SPSS 19.0 version.

\section{Results}

Total of 241 patients who agreed to take part in the study were enrolled.

159 patients were males (65.9\%) and $82(34.1 \%)$ patients were females.

Age of the patients ranged from 18-85 years.

$38(\mathrm{M}=27, \mathrm{~F}=11)(15.7 \%)$ of the 241 patients had urolithiasis (Table $2 \& 3$, Graph $2 \& 3$ ).

\begin{tabular}{|c|c|c|c|}
\hline Gender & & Male & Female \\
\hline \multirow{2}{*}{ Urolithiasis } & Yes & 27 & 11 \\
\cline { 2 - 4 } & No & 132 & 71 \\
\hline
\end{tabular}

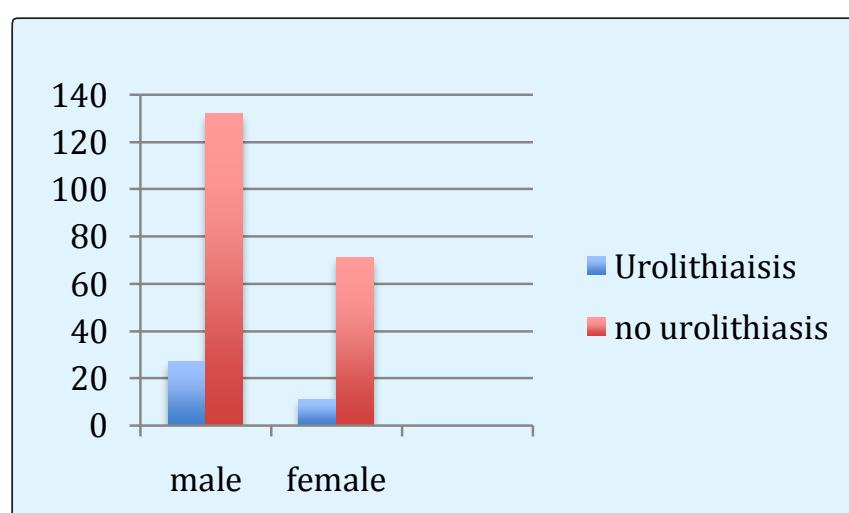

Table 2 \& Graph 2: Showing Gender distribution.

\begin{tabular}{|c|c|c|}
\hline Age Group & Number of Cases & $\begin{array}{c}\text { Number with } \\
\text { Urolithiasis }\end{array}$ \\
\hline$<20$ & 5 & 1 \\
\hline $20-40$ & 64 & 8 \\
\hline $40-60$ & 131 & 21 \\
\hline $60-80$ & 37 & 7 \\
\hline$>80$ & 4 & 1 \\
\hline
\end{tabular}

Philipraj SJ, et al. Association between Metabolic Syndrome and Urolithiasis- Descriptive Study. J Urol Nephrol 2018, 3(4): 000149.

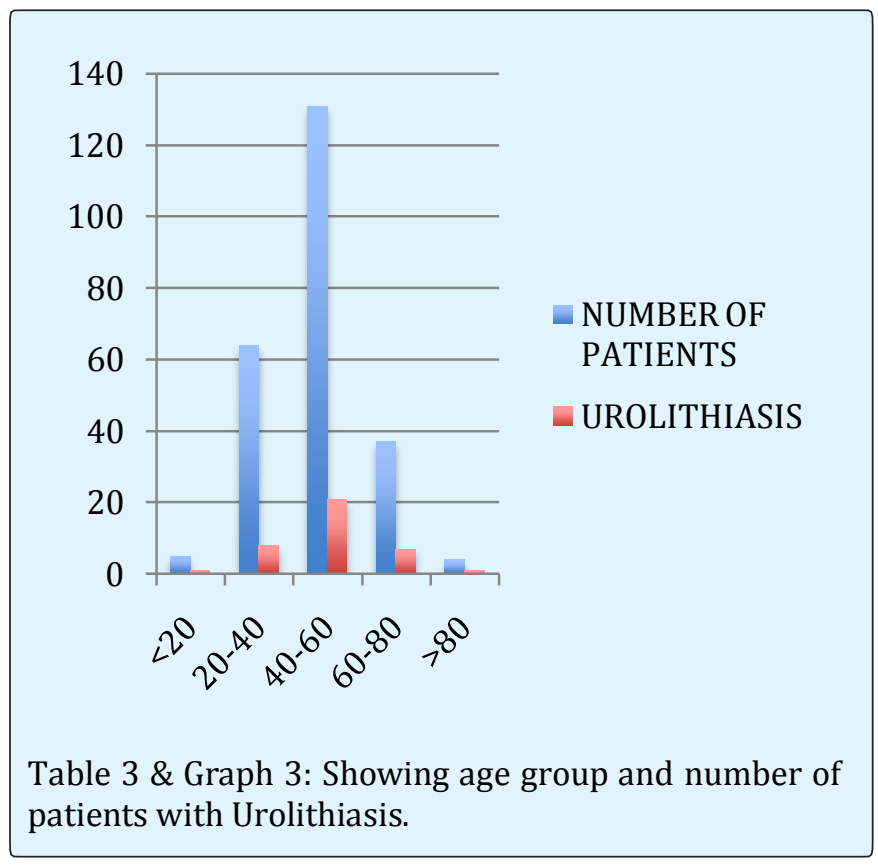

\section{Triglycerides \& Urolithiasis}

69 patients had Triglycerides $>150$ out of which 19 patients had urolithiasis (27.5\%).

172 patients had Triglycerides <150 Out of which 19 patients had urolithiasis (11.04\%) (Table 4 \& Graph 4).

\begin{tabular}{|c|c|c|c|}
\hline TG & & $>\mathbf{1 5 0}$ & $<\mathbf{1 5 0}$ \\
\hline \multirow{2}{*}{ Urolithiasis } & Yes & 19 & 19 \\
\cline { 2 - 4 } & No & 50 & 153 \\
\hline
\end{tabular}

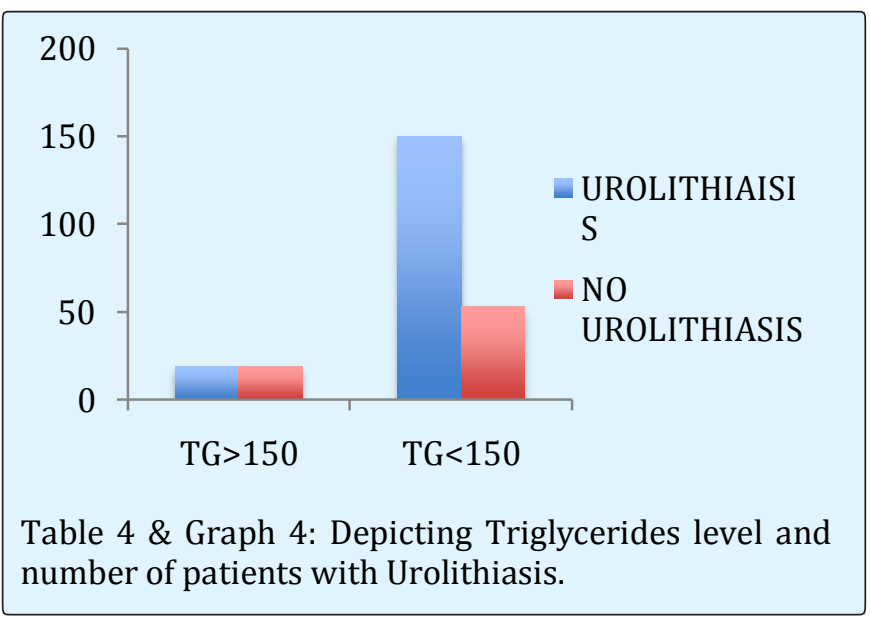

\section{Diabetes Mellitus and Urolithiasis}

57 patients were Diabetics and Out of these 8 patients had urolithiasis (14\%).

184 patients were non-diabetics and 30 of them had urolithiasis (19\%) (Table 5 \& Graph 5). 


\begin{tabular}{|c|c|c|c|}
\hline \multicolumn{2}{|c|}{ Diabetes } & Yes & No \\
\hline \multirow{2}{*}{ Urolithiasis } & Yes & 8 & 30 \\
\cline { 2 - 4 } & No & 49 & 154 \\
\hline
\end{tabular}

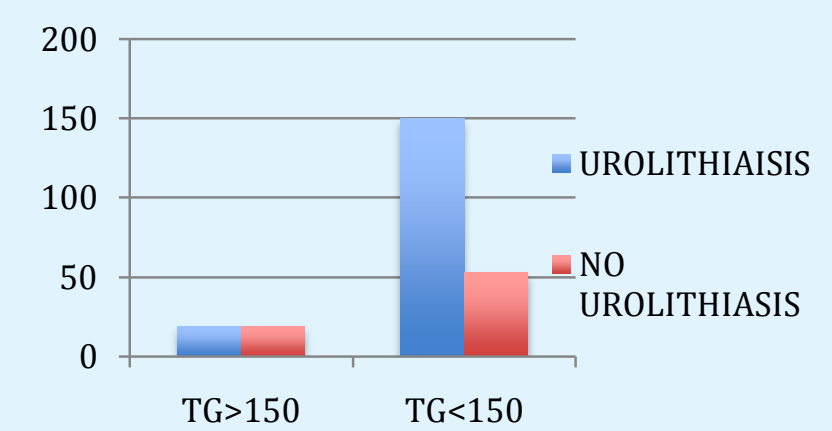

Table 5 \& Graph 5: Showing incidence of diabetes and urolithiasis.

\section{Systemic Hypertension and Urolithiasis}

54 patients were found to be hypertensive of which 9 patients had urolithiasis (16\%). 187 patients were normotensive of which 29 had urolithiasis (17\%) (Table 6 \& Graph 6).

\begin{tabular}{|c|c|c|c|}
\hline Hypertension & & Yes & No \\
\hline \multirow{2}{*}{ Urolithiasis } & Yes & 9 & 29 \\
\cline { 2 - 4 } & No & 45 & 158 \\
\hline
\end{tabular}

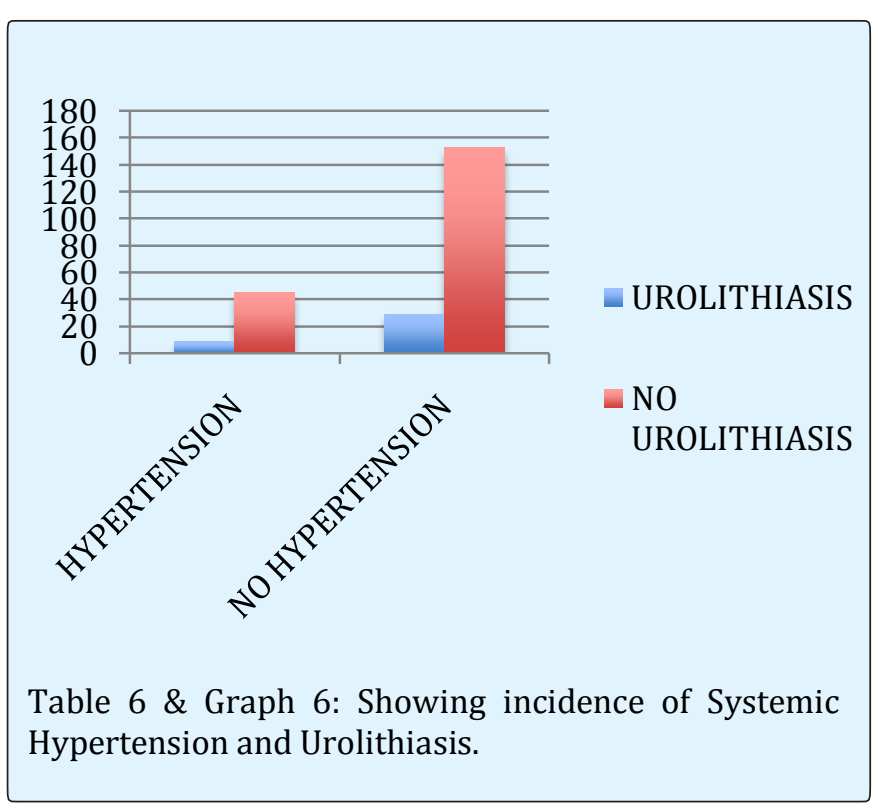

BMI and Urolithiasis

\begin{tabular}{|c|c|c|c|c|c|c|c|}
\hline \multicolumn{2}{|c|}{ BMI } & Underweight & Normal & Pre-obese & Obesity 1 & Obesity 2 & Obesity 3 \\
\cline { 3 - 8 } & & $<\mathbf{1 8 . 5}$ & $\mathbf{1 8 . 5 - 2 4 . 9}$ & $\mathbf{2 5 - 2 9 . 9}$ & $\mathbf{3 0 - 3 4 . 9}$ & $\mathbf{3 5 - 3 9 . 9}$ & $\mathbf{2 4 0}$ \\
\hline \multirow{2}{*}{ Urolithiasis } & Yes & 0 & 9 & 18 & 6 & 4 & 1 \\
\cline { 2 - 8 } & No & 7 & 59 & 96 & 28 & 10 & 3 \\
\hline
\end{tabular}

Total no of patients with BM I $<18.5$ were 7 out of which none had urolithiasis.

Total no of patients with BMI 18.5-24.9 were 75 of which 9 (13.2\%) had urolithiasis.

Out of 75 patients who were well within the Normal BMI range 9 patients had urolithiasis-12\%.

Total no of patients with BMI 25-29.9 were 114 out of which $18(15.7 \%)$ had urolithiasis

Total no of patients with BMI 30-34.9 were 34 out of which $6(17.6 \%)$ had urolithiasis.

Total no of patients with BMI 35-39.9 were 14 out of which $4(28.5 \%)$ had urolithiasis.

Total no of patients with BMI $\geq 40$ were 4 out of which $1(25 \%)$ had urolithiasis.

Out of 166 patients who had high BMI 29 had urolithiasis (17.5\%) (Table 7 \& Graph 7).

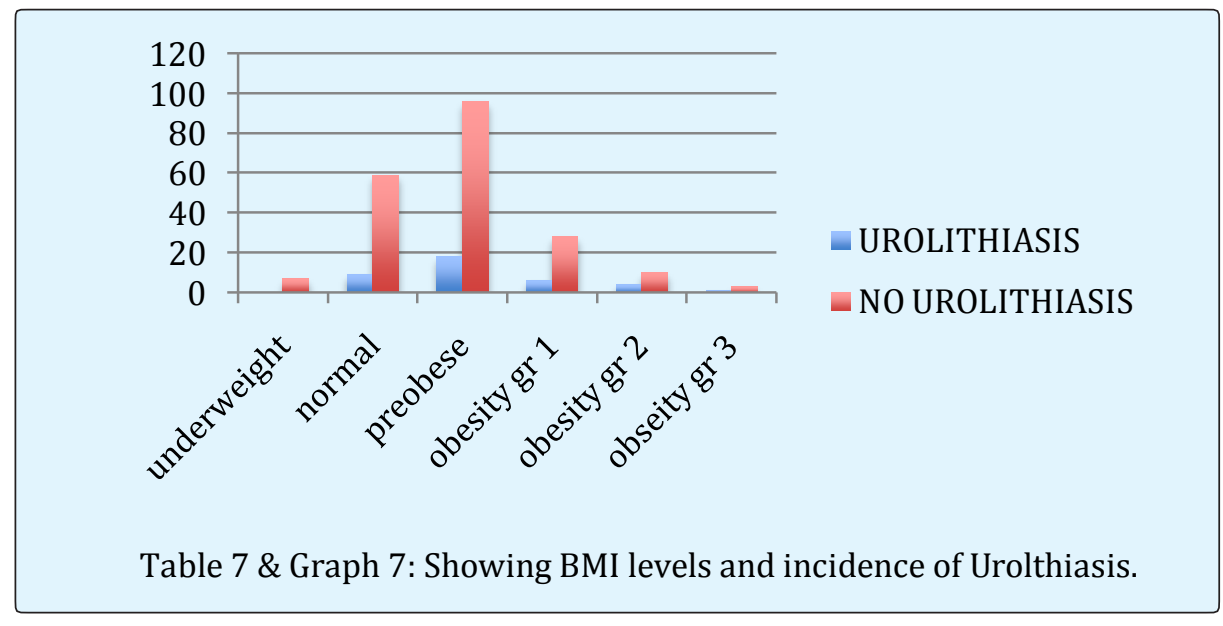




\section{HDL and Urolithiasis}

\begin{tabular}{|c|c|c|c|c|c|}
\hline & & \multicolumn{2}{|c|}{ Men } & \multicolumn{2}{c|}{ Women } \\
\hline \multirow{2}{*}{ HDL } & & $<40 \mathrm{mg} / \mathrm{dl}$ & $\begin{array}{c}> \\
40 \mathrm{mg} / \mathrm{dl} .\end{array}$ & $<50 \mathrm{mg} / \mathrm{dl}$ & $50 \mathrm{mg} / \mathrm{dl}$ \\
\hline \multirow{2}{*}{ Urolithiasis } & Yes & 4 & 23 & 5 & 6 \\
\cline { 2 - 6 } & No & 11 & 121 & 27 & 44 \\
\hline
\end{tabular}

Out of 15 male patients with $\mathrm{HDL}<40,4(26.7 \%)$ had urolithiasis

Out of 144 male patients with HDL>40, 23(15.9\%) had urolithiasis

Out of 32 female patients with $\mathrm{HDL}<50,5(15.6 \%)$ had urolithiasis

Out of 50 female patients with $\mathrm{HDL}>50,6(12 \%)$ had urolithiasis (Table 8 \& Graph 8).

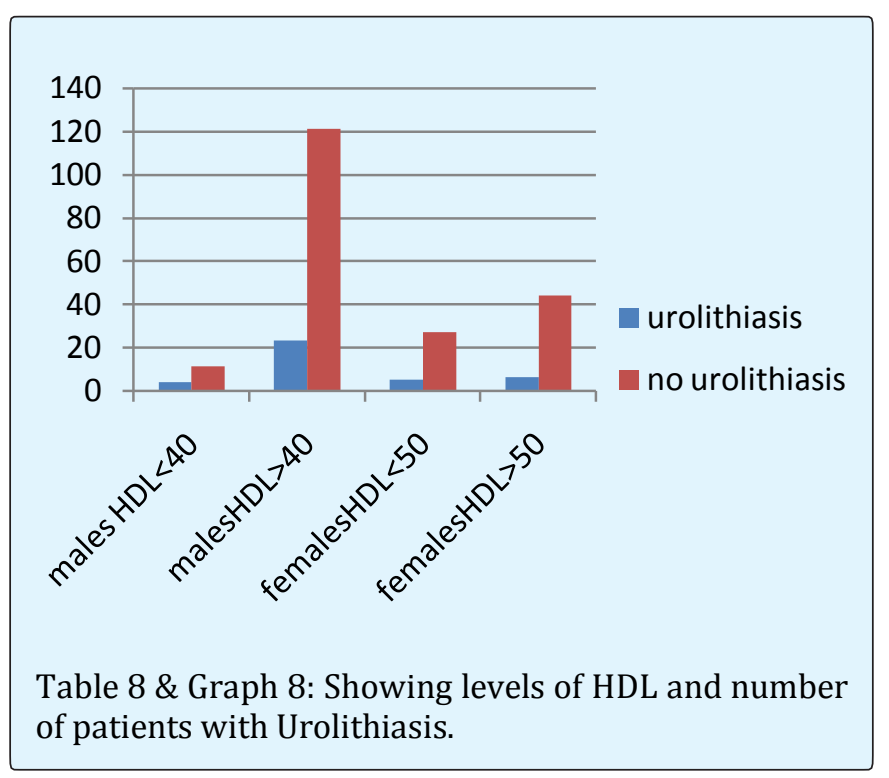

\section{Confounding Variables}

\section{Smoking and Urolithiasis}

\begin{tabular}{|c|c|c|c|}
\hline Smokers & & Yes & No \\
\hline \multirow{2}{*}{ Urolithiasis } & Yes & 14 & 24 \\
\cline { 2 - 4 } & No & 24 & 179 \\
\hline
\end{tabular}

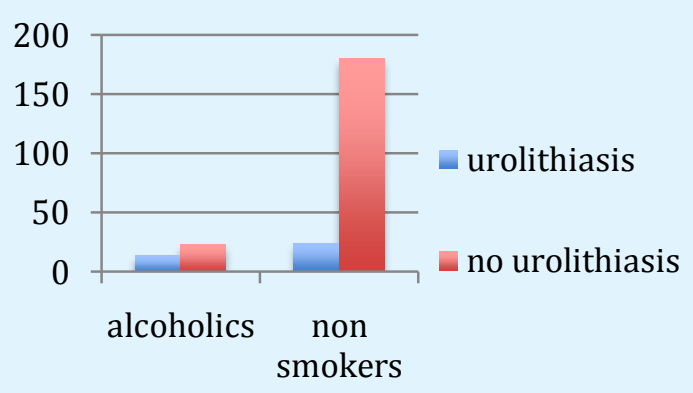

Table 9 \& Graph 9: Showing the Number of Smokers and number of patients with Urolithiasis.

\section{Alcoholism and Urolithiasis}

\begin{tabular}{|c|c|c|c|}
\hline Alcohol & & Yes & No \\
\hline \multirow{2}{*}{ Urolithiasis } & Yes & 14 & 24 \\
\cline { 2 - 4 } & No & 33 & 170 \\
\hline
\end{tabular}

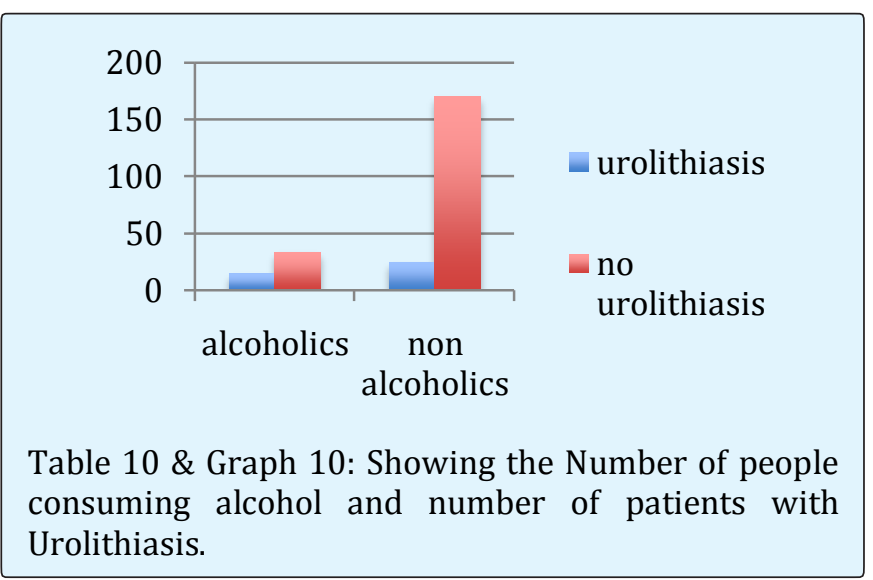

\section{Statistical Analysis}

The study is about observing the association between the metabolic syndrome and Urolithiasis. The parameters assessed were WC, SHT, TG, HDL, BMI and DM. All these were coded and were nominal variables. In order to observe the association, the appropriate statistical test is Chi-Square test was used and all the results were compared at 0.05 confidence level. Confounding Variables like smoking and alcoholism were also analysed. The entire analysis is carried out using IBM SPSS 19.0 version.

\begin{tabular}{|c|c|c|c|c|c|}
\hline \multirow{2}{*}{$\begin{array}{c}\text { WC * DIAGNOSIS Cross } \\
\text { tabulation }\end{array}$} & \multicolumn{2}{|c|}{ DIAGNOSIS } & \multirow{2}{*}{ Total } \\
\cline { 3 - 5 } & \multirow{3}{*}{$* 100$} & Count & 130 & 25 & 155 \\
\cline { 3 - 5 } & & $\%$ within WC & $83.90 \%$ & $16.10 \%$ & $100.00 \%$ \\
\cline { 2 - 5 } WC & & $\%$ within DIAGNOSIS & $64.00 \%$ & $65.80 \%$ & $64.30 \%$ \\
\cline { 2 - 5 } & \multirow{2}{*}{$>100$} & Count & 73 & 13 & 86 \\
\cline { 2 - 5 } & & \% within WC & $84.90 \%$ & $15.10 \%$ & $100.00 \%$ \\
\hline
\end{tabular}




\begin{tabular}{|c|c|c|c|c|c|}
\hline & \% within DIAGNOSIS & $36.00 \%$ & $34.20 \%$ & $35.70 \%$ \\
\hline \multirow{3}{*}{ Total } & Count & 203 & 38 & 241 \\
\cline { 2 - 5 } & & \% within WC & $84.20 \%$ & $15.80 \%$ & $100.00 \%$ \\
\cline { 2 - 5 } & \% within DIAGNOSIS & $100.00 \%$ & $100.00 \%$ & $100.00 \%$ \\
\hline
\end{tabular}

Chi-square $=0.043$, $\mathrm{p}$-value $=0.836^{\mathrm{NS}}$.

Table 11: Cross Tabulation \& Association between WC and Urolithiasis.

In Table 12, the association between Diabetes mellitus (DM) and Diagnosis is observed to be insignificant with pvalue is $0.875(>0.05)$. This outlines the fact that absence/presence of DM does not support to relate the urolithiasis.

\begin{tabular}{|c|c|c|c|c|c|}
\hline \multirow{2}{*}{\multicolumn{3}{|c|}{ DM * Urolithiasis Cross tabulation }} & \multicolumn{2}{|c|}{ DIAGNOSIS } & \multirow{3}{*}{$\begin{array}{c}\text { Total } \\
188 \\
\end{array}$} \\
\hline & & & other cases & urolithiasis & \\
\hline \multirow{6}{*}{ DM } & \multirow{3}{*}{ no } & Count & 158 & 30 & \\
\hline & & \% within DM & $84.00 \%$ & $15.90 \%$ & $100.00 \%$ \\
\hline & & \% within diagnosis & $77.83 \%$ & $78.90 \%$ & $78.00 \%$ \\
\hline & \multirow{3}{*}{ yes } & Count & 45 & 8 & 53 \\
\hline & & \% within DM & $84.90 \%$ & $14.00 \%$ & $100.00 \%$ \\
\hline & & \% within DIAGNOSIS & $22.16 \%$ & $21.05 \%$ & $21.99 \%$ \\
\hline \multirow{3}{*}{\multicolumn{2}{|c|}{ Total }} & Count & 203 & 38 & 241 \\
\hline & & \% within DM & $84.20 \%$ & $15.70 \%$ & $100.00 \%$ \\
\hline & & \% within diagnosis & $100.00 \%$ & $100.00 \%$ & $100.00 \%$ \\
\hline
\end{tabular}

Chi-square $=0.025 ;$ p-value $=0.875^{\mathrm{NS}}$.

Table 12: Cross Tabulation \& Association between DM and Urolithiasis.

In Table 13, the results show an insignificant p-value $0.642(>0.05)$, giving rise to the fact that even the

categories of SHT cannot be used to determine the outcome of the diagnosis.

\begin{tabular}{|c|c|c|c|c|c|}
\hline \multirow{2}{*}{\multicolumn{3}{|c|}{ SHT * DIAGNOSIS Cross tabulation }} & \multicolumn{2}{|c|}{ DIAGNOSIS } & \multirow{3}{*}{$\begin{array}{c}\text { Total } \\
187\end{array}$} \\
\hline & & & \multirow{2}{*}{$\begin{array}{c}\text { other cases } \\
158\end{array}$} & \multirow{2}{*}{$\frac{\text { urolithiasis }}{29}$} & \\
\hline \multirow{6}{*}{ SHT } & \multirow{3}{*}{ No } & Count & & & \\
\hline & & \% within SHT & $84.40 \%$ & $15.50 \%$ & $100.00 \%$ \\
\hline & & $\%$ within DIAGNOSIS & $77.80 \%$ & $76.30 \%$ & $78.60 \%$ \\
\hline & \multirow{3}{*}{ yes } & Count & 45 & 9 & 54 \\
\hline & & \% within SHT & $83.30 \%$ & $16.70 \%$ & $100.00 \%$ \\
\hline & & \% within DIAGNOSIS & $22.10 \%$ & $23.60 \%$ & $21.40 \%$ \\
\hline \multirow{3}{*}{\multicolumn{2}{|c|}{ Total }} & Count & 203 & 38 & 241 \\
\hline & & \% within SHT & $84.20 \%$ & $15.70 \%$ & $100.00 \%$ \\
\hline & & \% within DIAGNOSIS & $100.00 \%$ & $100.00 \%$ & $100.00 \%$ \\
\hline
\end{tabular}

Chi-square $=0.216 ;$ p-value $=0.642^{\mathrm{NS}}$.

Table 13: Cross Tabulation \& Association between SHT and Urolithiasis.

In Table 14, the results show significant p-value 0.008 $(<0.05)$, implies the fact that categories of TG can be used to determine the outcome of the diagnosis. The outcome of TG can be associated with the urolithiasis, and equal percentage of patients is distributed across two categories of TG. 


\section{Open Access Journal of Urology \& Nephrology}

\begin{tabular}{|c|c|c|c|c|c|}
\hline \multirow{2}{*}{\multicolumn{3}{|c|}{ TG * DIAGNOSIS Cross tabulation }} & \multicolumn{2}{|c|}{ DIAGNOSIS } & \multirow{3}{*}{$\begin{array}{c}\text { Total } \\
172\end{array}$} \\
\hline & & & other cases & urolithiasis & \\
\hline \multirow{6}{*}{ TG } & \multirow{3}{*}{$<150$} & Count & 153 & 19 & \\
\hline & & $\%$ within TG & $88.95 \%$ & $11.04 \%$ & $100.00 \%$ \\
\hline & & \% within DIAGNOSIS & $74.00 \%$ & $50.00 \%$ & $71.36 \%$ \\
\hline & \multirow{3}{*}{$>150$} & Count & 50 & 19 & 69 \\
\hline & & $\%$ within $\mathrm{TG}$ & $72.40 \%$ & $27.53 \%$ & $100.00 \%$ \\
\hline & & $\%$ within DIAGNOSIS & $24.63 \%$ & $50.00 \%$ & $28.63 \%$ \\
\hline \multirow{3}{*}{\multicolumn{2}{|c|}{ Total }} & Count & 203 & 38 & 241 \\
\hline & & $\%$ within $\mathrm{TG}$ & $86.30 \%$ & $13.70 \%$ & $100.00 \%$ \\
\hline & & \% within DIAGNOSIS & $100.00 \%$ & $100.00 \%$ & $100.00 \%$ \\
\hline
\end{tabular}

Chi-square $=7.011 ; \mathrm{p}$-value $=0.008$ s

Table 14: Cross Tabulation \& Association between TG and Urolithiasis.

In Table 15, the results show an insignificant p-value 0.790 (>0.05), giving rise to the fact that even the

categories of HDL cannot be used to determine the outcome of the diagnosis.

\begin{tabular}{|c|c|c|c|c|c|}
\hline \multirow{2}{*}{\multicolumn{3}{|c|}{ HDL * DIAGNOSIS Cross tabulation }} & \multicolumn{2}{|c|}{ DIAGNOSIS } & \multirow{3}{*}{$\begin{array}{c}\text { Total } \\
194 \\
\end{array}$} \\
\hline & & & other cases & urolithiasis & \\
\hline \multirow{6}{*}{ HDL } & \multirow{3}{*}{$>40$} & Count & 165 & 29 & \\
\hline & & $\%$ within HDL & $85.05 \%$ & $14.94 \%$ & $100.00 \%$ \\
\hline & & $\%$ within DIAGNOSIS & $81.20 \%$ & $76.30 \%$ & $80.50 \%$ \\
\hline & \multirow{3}{*}{$<40$} & Count & 38 & 9 & 47 \\
\hline & & $\%$ within HDL & $85.10 \%$ & $14.90 \%$ & $100.00 \%$ \\
\hline & & \% within DIAGNOSIS & $18.70 \%$ & $23.60 \%$ & $19.50 \%$ \\
\hline \multirow{3}{*}{\multicolumn{2}{|c|}{ Total }} & Count & 203 & 38 & 241 \\
\hline & & \% within HDL & $84.20 \%$ & $15.70 \%$ & $100.00 \%$ \\
\hline & & \% within DIAGNOSIS & $100.00 \%$ & $100.00 \%$ & $100.00 \%$ \\
\hline
\end{tabular}

Chi-square $=0.071 ;$-value $=0.790^{\mathrm{NS}}$.

Table 15: Cross tabulation and Association between HDL and Urolithiasis.

In Table $16 \& 17$, the results show significant $p$-value $(<0.05)$, implies the fact that categories of SMOKING and ALCOHOL can be used to determine the outcome of the diagnosis. Of 38 of patients under urolithiasis, majority of patients have the habit of smoking. With this phenomenon, one can associate that people who smoke regularly or occasionally have the likelihood of observing urolithiasis. Similar kind of interpretation can be drawn for the status of alcohol.

\begin{tabular}{|c|c|c|c|c|c|}
\hline \multirow{2}{*}{\multicolumn{3}{|c|}{ SMOKING * Urolithiasis Cross tabulation }} & \multicolumn{2}{|c|}{ DIAGNOSIS } & \multirow{3}{*}{$\begin{array}{c}\text { Total } \\
204\end{array}$} \\
\hline & & & other cases & urolithiasis & \\
\hline \multirow{9}{*}{ SMOKING } & \multirow{3}{*}{ No } & Count & 180 & 24 & \\
\hline & & $\%$ within SMOKING & $88.20 \%$ & $11.80 \%$ & $100.00 \%$ \\
\hline & & \% within Urolithiasis & $87.40 \%$ & $67.60 \%$ & $84.50 \%$ \\
\hline & \multirow{3}{*}{ Yes } & Count & 22 & 11 & 33 \\
\hline & & \% within SMOKING & $71.40 \%$ & $28.60 \%$ & $100.00 \%$ \\
\hline & & \% within Urolithiasis & $11.70 \%$ & $27.00 \%$ & $13.90 \%$ \\
\hline & \multirow{3}{*}{ Occasional } & Count & 1 & 3 & 4 \\
\hline & & \% within SMOKING & $50.00 \%$ & $50.00 \%$ & $100.00 \%$ \\
\hline & & \% within Urolithiasis & $0.90 \%$ & $5.40 \%$ & $1.60 \%$ \\
\hline \multirow{3}{*}{\multicolumn{2}{|c|}{ Total }} & Count & 204 & 37 & 241 \\
\hline & & \% within SMOKING & $85.30 \%$ & $14.70 \%$ & $100.00 \%$ \\
\hline & & \% within Urolithiasis & $100.00 \%$ & $100.00 \%$ & $100.00 \%$ \\
\hline
\end{tabular}

Chi-square $=10.750 ;$ p-value $=0.005^{\mathrm{s}}$.

Table 16: Cross Tabulation \& Association between Smoking and Urolithiasis. 


\section{Open Access Journal of Urology \& Nephrology}

\begin{tabular}{|c|c|c|c|c|c|}
\hline \multirow{2}{*}{\multicolumn{3}{|c|}{ ALCOHOL * DIAGNOSIS Cross tabulation }} & \multicolumn{2}{|c|}{ DIAGNOSIS } & \multirow{2}{*}{ Total } \\
\hline & & & other cases & Urolithiasis & \\
\hline \multirow{9}{*}{ ALCOHOL } & \multirow{3}{*}{ No } & Count & 170 & 24 & 194 \\
\hline & & $\%$ within ALCOHOL & $87.60 \%$ & $12.30 \%$ & $100.00 \%$ \\
\hline & & \% within DIAGNOSIS & $83.70 \%$ & $63.10 \%$ & $80.40 \%$ \\
\hline & \multirow{3}{*}{ Yes } & Count & 29 & 9 & 38 \\
\hline & & \% within ALCOHOL & $82.90 \%$ & $17.10 \%$ & $100.00 \%$ \\
\hline & & $\%$ within DIAGNOSIS & $14.20 \%$ & $23.60 \%$ & $15.70 \%$ \\
\hline & \multirow{3}{*}{ Occasional } & Count & 4 & 5 & 9 \\
\hline & & $\%$ within ALCOHOL & $40.00 \%$ & $60.00 \%$ & $100.00 \%$ \\
\hline & & \% within DIAGNOSIS & $1.90 \%$ & $13.10 \%$ & $4.00 \%$ \\
\hline \multirow{3}{*}{\multicolumn{2}{|c|}{ Total }} & Count & 203 & 38 & 241 \\
\hline & & \% within ALCOHOL & $85.30 \%$ & $14.70 \%$ & $100.00 \%$ \\
\hline & & \% within DIAGNOSIS & $100.00 \%$ & $100.00 \%$ & $100.00 \%$ \\
\hline
\end{tabular}

Chi-square $=17.671 ; \mathrm{p}$-value $=0.000^{\mathrm{s}}$.

Table 17: Cross Tabulation \& Association between Alcoholism and Urolithiasis.

The influence of smoking and alcoholism on urolithiasis has only been scarcely examined [24-26]. Furthermore, there is no consistent evidence about the effects of smoking and alcoholism on urolithiasis. In the present study there was significant relationship between modifiable risk factors, such as smoking and alcoholism on urolithiasis.

\section{Discussion and Conclusion}

In this study, the risk factors for urolithiasis were male gender, Hypertriglyceridemia, smoking and alcoholism and they were statistically significant. We found no relationship between Hypertension, Diabetes Mellitus, Waist circumference, Low Density lipoproteins and urolithiasis. We also did not find statistically significant correlation between BMI and urolithiasis, which is in frank contrast with numerous studies from western literature that demonstrated a positive relationship between obesity and urolithiasis. Smoking and Alcoholism seems to have statistical correlation. The study consists of relatively small number of patients. A study with larger numbers is needed to verify the correlation between metabolic syndrome and urolithiasis.

\section{References}

1. Romero V, Akpinar H, Assimos DG (2010) Kidney stones: a global picture of prevalence, incidence, and associated risk factors. Rev Urol 12(2-3): 86-96.

2. Bartoletti R, Cai T, Mondaini N, Melone F, Travaglini F, et al. (2007) Epidemiology and risk factors in urolithiasis. Urol Int 79(1): 3-7.
3. Sofia NH, Manickavasakam K, Walter TM (2016) PREVALENCE AND RISK FACTORS OF KIDNEY STONE. Global journal for Research Analysis.

4. James PT, Leach R, Kalamara E, Shayeghi M (2001) Theworld- wide obesity epidemic. Obesity Research 9(4): 228s-233s.

5. Antonelli JA, Maalouf NM, Pearle MS, Lotan Y (2014) Use of the national health and nutrition examination survey to calculate the impact of obesity and diabetes on cost and prevalence of urolithiasis in 2030. Eur Urol 66(4): 724-729.

6. Alberti KG, Eckel RH, Grundy SM, Zimmet PZ, Cleeman JI, et al. (2009) Harmonizing the meta- bolic syndrome: a joint interim statement of the International Diabetes Federation Task Force on Epidemiology and Prevention; National Heart, Lung, and Blood Institute; American Heart Association; World Heart Federation; International Atherosclerosis Society; and International Association for the Study of Obesity. Circulation 120(16): 16401645.

7. Wong YV, Cook P, Soman BK (2015) The Association of Metabolic Syndrome and Urolithiasis. International Journal of Endocrinology.

8. Besiroglu H, Otunctemur A, Ozbek E (2015) The metabolic syndrome and urolithiasis: a systematic review and meta-analysis. Ren Fail 37(1): 1-6.

9. Taylor EN, Stampfer MJ, Curhan GC (2005) Obesity, weight gain, and the risk of kidney stones. JAMA 293(4): 455-462. 
10. Taylor EN, Stampfer MJ, Curhan GC (2005) Diabetes mellitus and the risk of nephrolithiasis. Kidney Int 68(3): 1230-1235.

11. Curhan GC, Willett WC, Rimm EB, Speizer FE, Stampfer MJ (1998) Body size and risk of kidney stones. J Am Soc Nephrol 9(9): 1645-1652.

12. Hammarsten J, Damber JE, Peeker R, Mellström D, Högstedt B (2010) A higher prediagnostic insulin level is a prospective risk factor for incident prostate cancer. Cancer Epidemiol 34(5): 574-579.

13. Hammarsten J, Högstedt B (2004) Clinical, hemodynamic, anthropometric, metabolic and insulin profile of men with high stage and high grade clinical prostate cancer. Blood Press 13(1): 47-55.

14. Hammarsten J, Damber JE, Karlsson M, Knutson T, Ljunggren 0 , et al. (2009) Insulin and free estradiol are independent risk factors for benign prostatic hyperplasia. Prostate Cancer Prostate Dis 12(2): 160165.

15. Parsons JK, Carter HB, Partin AW, Windham BG, Metter EJ, et al. (2006) Metabolic factors associated with benign prostatic hyperplasia. J Clin Endocrinol Metab 91(7): 2562-2568.

16. Reavan GM (1988) Banting lecture 1988. Role of insulin resistance in human disease. Diabetes 37(12): 1595-1607.

17. Reaven GM (1994) Syndrome X: 6 years later. J Int Med 736: 13-22.

18. Stone NJ, Robinson J, Lichtenstein AH, Bairey Merz CN, Blum CB, et al. (2014) 2013 ACC/AHA guideline on the treatment of blood cholesterol to reduce atherosclerotic cardiovascular risk in adults: a report of the American College of Cardiology/American Heart Association Task Force on Practice Guidelines. Circulation 63(25Pt B): 2889-2934.

19. International Chair on Cardiometabolic Risk. Metabolic Syndrome and Type 2 Diabetes/CVD Risk (2014).

20. Alexander CM, Landsman PB, Teutsch SM, Haffner SM (2003) NCEP-defined metabolic syndrome, diabetes, and prevalence of coronary heart disease among NHANES III participants age 50 years and older. Diabetes 52(5): 1210-1214.

21. Alberti KGMM, Zimmet P, Shaw J (2005) The metabolic syndrome-a new worldwide definition. The Lancet 366(9491): 1059-1062.

22. International Diabetes Federation. The IDF consensus worldwide definition of metabolic syndrome.

23. Atan A (2017) Metabesity and urological Cancers. Turk J Urol 43(4): 410-413.

24. Tamadon MR, Nassaji M, Ghorbani R (2013) Cigarette smoking and nephrolithiasis in adult individuals. Nephrourol Mon 5(1): 702-705.

25. Liu CC, Huang SP, Wu WJ, Chou YH, Juo SH, et al. (2009) The impact of cigarette smoking, alcohol drinking and betel quid chewing on the risk of calcium urolithiasis. Ann Epidemiol 19(8): 539-545.

26. Hamano S, Nakatsu H, Suzuki N, Tomioka S, Tanaka $\mathrm{M}$, et al. (2005) Kidney stone disease and risk factors for coronary heart disease. Int J Urol 12(10): 859-863.

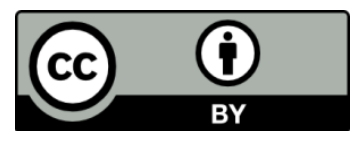

